EGU21-7390

https://doi.org/10.5194/egusphere-egu21-7390

EGU General Assembly 2021

(c) Author(s) 2021. This work is distributed under

the Creative Commons Attribution 4.0 License.

\title{
Acoustical reconstruction and thunder energy localisation in lightning flashes measured over Corsica during EXAEDRE field campaign
}

\author{
Damien Bestard ${ }^{1}$, Thomas Farges ${ }^{2}$, and François Coulouvrat ${ }^{1}$ \\ ${ }^{1}$ Institut Jean Le Rond d'Alembert, Sorbonne Université, UMR CNRS 7190, 4 place Jussieu 75005 Paris \\ ${ }^{2}$ CEA, DAM, DIF F-91297 Arpajon, France
}

From September 13th to October 12th 2018, the EXAEDRE field campaign took place in Corsica, dedicated to the characterisation of thunderstorm clouds and electrical activity. Among a wide range of observation instruments, an array of 4 microphones, arranged on a 30-m wide triangle located near the island eastern coast, recorded over the frequency band 1 to $80 \mathrm{~Hz}$ the acoustical signal, or thunder, associated to lightning flashes. The search for coherent signals between the four sensors within prescribed frequency bands allows to determine the thunder apparent sound velocity and azimuth (PMCC algorithm [1]). Knowing the flash emission time provided by Meteorage low frequency (1-350 kHz) electromagnetic ground lightning locating system, as well as the local speed of sound, it is possible to reconstruct the various positions of coherent sound sources within a single lightning flash. Co-localisation of acoustic sources with in-cloud detections provided by SAETTA high-frequency $(60-66 \mathrm{MHz})$ electromagnetic lightning locating system, and with ground impacts provided by Meteorage, ensures the efficiency and precision of the method. This one was already used successfully in a previous field campaign (HyMeX-SOP1) in Cévennes in $2012[2,3,4]$. The detection algorithm PMCC also provides the various recorded signal intensities. Assuming each sound point source radiates a spherical wave, the different propagation distances between the sources and the recording array can be compensated, so that the thunder source energies can also be localised within the flash with their relative levels. For EXAEDRE, two storms have been studied from an acoustical point of view, one with a low electrical activity on October 2nd mainly over the Mediterranean sea, and one with an intense activity on 17th September mainly overland. A significant number of flash events has been analysed, reconstructed and their energy distribution determined. For the 17th of September, acoustical events of large amplitudes are well correlated to (mostly negative) Cloud to Ground flash events. Energy localisation indicates a strong heterogeneity of its distribution within the flash, with intense sound sources concentrated inside the return strokes, mostly within the two first kilometres above the ground. Intracloud parts of the flashes appear much less energetic from an acoustical point of view. For the 2nd October, overversea events turn out quite different. [The authors acknowledge the EXAEDRE program, lead by E. Defer, for supplying the data. Present results have been obtained within the frame of the LETMA Contractual Research Laboratory between CEA, CNRS, Ecole Centrale Lyon, C-Innov, and Sorbonne Université.] 
[1] Y. Cansi, Geophys. Res. Lett., 22, 1021-1024, 1995

[2] L.J. Gallin, Th. Farges, R. Marchiano, F. Coulouvrat, E. Defer, W. Rison, W. Schulz, M. Nuret, J. Geophys. Res. Atmos., 121, 3929-3953, 2016

[3] A. Lacroix, Th. Farges, R. Marchiano, F. Coulouvrat, J. Geophys. Res. Atmos., 123, 12040-12065, 2018

[4] A. Lacroix, F. Coulouvrat, R. Marchiano, Th. Farges, J.-F. Ripoll, Geophys. Res. Lett., 46, 11479-11489, 2019 